\title{
Family burden in schizophrenia: the influence of age of onset and negative symptoms
}

\author{
Sobrecarga familiar na esquizofrenia: a influência da idade de início e dos \\ sintomas negativos
}

\author{
Lucas M. Mantovani, ${ }^{1,2}$ Rodrigo Ferretjans, ${ }^{2}$ Iara M. Marçal, ${ }^{1,2}$ Amanda M. Oliveira, ${ }^{1,2}$ Fernanda C. Guimarães, ${ }^{1,2}$ \\ João Vinícius Salgado ${ }^{1,2,3}$
}

\begin{abstract}
Objectives: To investigate the determinants of family burden in a sample of patients with schizophrenia and their caregivers. Methods: Thirty-one stable patients with schizophrenia and their main caregivers were recruited. Sociodemographic variables were assessed in a semi-structured interview, and positive and negative symptoms were assessed with the Positive and $\mathrm{Ne}$ gative Syndrome Scale (PANSS). Cognitive performance was assessed with the Schizophrenia Cognition Rating Scale (SCoRS). Levels of burden on caregivers were assessed with the Family Burden Interview Schedule (FBIS). Interactions among variables were analyzed using Pearson correlations and linear regression analysis.

Results: Objective and subjective FBIS scores were 1.9 (standard deviation $[S D]=0.5)$ and $2.4(S D=0.6)$ respectively. Objective burden correlated positively with positive and negative symptoms, and cognitive impairment. Subjective burden correlated positively with positive symptoms and negatively with mean age of disease onset. Positive, negative and cognitive symptoms accounted for $47.6 \%$ of the variance of objective burden, with negative symptoms accounting independently for $30.3 \%$. Age of onset, parents as caregivers and positive symptoms accounted for $28 \%$ of the variance of subjective burden, with age of onset independently explaining $20.3 \%$.

Conclusion: Patients' clinical and sociodemographic variables are important determinants of family burden in schizophrenia. Objective burden is predicted by symptoms, particularly negative ones. Subjective burden is predicted by symptoms and sociodemographic variables, particularly age of disease onset.

Keywords: Schizophrenia, family burden, burden of illness, negative symptoms, age of onset, cognition.
\end{abstract}

\section{Resumo}

Objetivo: Investigar os determinantes de sobrecarga familiar numa amostra de pacientes com esquizofrenia e seus cuidadores.

Métodos: Trinta e um pacientes com esquizofrenia e seus principais cuidadores participaram do estudo. Variáveis sociodemográficas foram analisadas por meio de uma entrevista semiestruturada, e sintomas positivos e negativos foram quantificados através da Positive and Negative Syndrome Scale (PANSS). O desempenho cognitivo foi mensurado pela Schizophrenia Cognition Rating Scale (SCoRS). A Escala de Avaliação da Sobrecarga dos Familiares (FBIS) avaliou os níveis de sobrecarga entre os cuidadores. As interações entre as variáveis foram verificadas por meio do coeficiente de correlação de Pearson e de análise de regressão linear.

Resultados: Os escores objetivos e subjetivos da FBIS foram 1,9 [desvio padrão (DP) 0,5 ] e 2,4 (DP 0,6), respectivamente. Sobrecarga objetiva se correlacionou positivamente com sintomas positivos e negativos, e com prejuízos cognitivos. A sobrecarga subjetiva se correlacionou positivamente com sintomas positivos, e negativamente com a idade de início da doença. Os sintomas positivos e negativos e os prejuízos cognitivos contribuíram com $47,6 \%$ da variância da sobrecarga objetiva, sendo que sintomas negativos foram responsáveis independentemente por 30,3\%. A idade de início da doença, os pais na posição de cuidadores e os sintomas positivos contribuíram com $28 \%$ da variância da sobrecarga subjetiva, sendo que a idade de início da doença contribuiu independentemente com 20,3\%.

Conclusões: Variáveis sociodemográficas e clínicas dos pacientes são importantes determinantes de sobrecarga familiar na esquizofrenia. A sobrecarga objetiva pode ser predita por sintomas, especialmente os negativos. A sobrecarga subjetiva pode ser predita por sintomas e características sociodemográficas, particularmente a idade de início da doença.

Descritores: Esquizofrenia, sobrecarga familiar, sobrecarga do adoecimento, sintomas negativos, idade de início, cognição.

\footnotetext{
${ }^{1}$ Instituto Raul Soares, Fundação Hospitalar do Estado de Minas Gerais (FHEMIG), Belo Horizonte, MG, Brazil. ${ }^{2}$ Programa de Pós-Graduação em Neurociências, Instituto de Ciências Biológicas, Universidade Federal de Minas Gerais (UFMG), Belo Horizonte, MG, Brazil. ${ }^{3}$ Departamento de Morfologia, Instituto de Ciências Biológicas, UFMG, Belo Horizonte, MG, Brazil.

Financial support: FAPEMIG (APQ 00564-12). Iara M. Marçal and Amanda M. Oliveira receive scholarships from the Programa Interinstitucional de Bolsas de Iniciação Científica (PIBIC) at FAPEMIG/FHEMIG, Belo Horizonte, MG, Brazil.

Submitted Dec 02 2015, accepted for publication Feb 05 2016. No conflicts of interest declared concerning the publication of this article.

Suggested citation: Mantovani LM, Ferretjans R, Marçal IM, Oliveira AM, Guimarães FC, Salgado JV. Family burden in schizophrenia: the influence of age of onset and negative symptoms. Trends Psychiatry Psychother. 2016;38(2):96-99. http://dx.doi.org/10.1590/2237-6089-2015-0082
} 


\section{Introduction}

Schizophrenia is a major psychiatric disorder, strongly related to social and functioning deficits and is potentially harmful lifelong, for both patients and caregivers. ${ }^{1}$ In most cases, families are the main caregivers and often become overwhelmed by patients' care, which encompasses areas like personal care, management of medication and everyday functioning. Family burden is becoming increasingly recognized as a relevant concept in schizophrenia, since it can result in negative long-term outcomes. Burdened caregivers are potentially prone to high levels of expressed emotion, ${ }^{2}$ contributing to increased probability of new psychotic crises and hospitalizations.

The concept of family burden comprises two different but complementary subdomains. Objective family burden refers to the observable consequences of care, such as disturbances to family routines provoked by the illness. The subjective subdomain points to the emotional burden of care, such as feelings of guilt, and concerns about the future.

Different degrees of burden can be found across families, depending on patient, caregiver or environment features. Previous studies found that the patient's degree of disability, ${ }^{3}$ symptomatology, ${ }^{3-6}$ and gender ${ }^{3,6,7}$ predicted family burden. Among caregivers, coping abilities, ${ }^{4,6}$ educational level, 7 and relationship with patient (e.g., being a parent) ${ }^{6}$ accounted for significant variance in this outcome.

The aim of this study was to investigate the determinants of family burden in a preliminary sample of schizophrenia patients and their main caregivers. We hypothesized that objective and subjective burden would be differently predicted by clinical and sociodemographic variables. Positive, negative and cognitive symptoms, kinship between patient and caregiver (parent/nonparent), age of disease onset and the ratio between patient and family incomes were assessed.

\section{Method}

Thirty-one stable patients with schizophrenia and their main caregivers were recruited from a public service in the Belo Horizonte metropolitan area (Brazil). Diagnosis was confirmed by Mini International Neuropsychiatric Interview-Plus (MINI-Plus) ${ }^{8}$ using criteria from the Diagnostic and Statistical Manual of Mental Disorders, 4th edition, Text Revision (DSM-IV-TR). Clinical stability was defined as a Positive and Negative Syndrome Scale (PANSS) positive score of 19 or less (and scores below 4 on every single item of the positive scale). Moreover, for inclusion, patients had to be on regular treatment, defined as at least one visit to a physician's office every other month and on continuous use of antipsychotic medication, as prescribed. The main caregiver was defined as the person responsible for supervision of relevant activities of everyday functioning. The local Ethics Research Committee approved the study.

Data on sociodemographic variables were collected in a semi-structured interview and positive and negative symptoms were assessed with the PANSS. ${ }^{9}$ Cognitive performance was assessed with the interviewer's rating of the Schizophrenia Cognition Rating Scale (SCoRS), which takes into account both the patient's and the informant's answers. ${ }^{10}$ For PANSS and SCoRS, higher values represent more severe symptoms and greater cognitive impairment, respectively.

The Family Burden Interview Schedule (FBIS) ${ }^{11}$ was employed to evaluate levels of burden. The instrument has five domains: assistance in daily life, supervision of problematic behavior, financial burden, impact on family routine and worries about present and future life. The financial burden domain is not computed in final scores, but provides useful additional information. Each domain is composed by items measuring either objective or subjective burden. Items measuring frequency of care assess objective burden, ranging from 1 (never) to 5 (every day), while subjective burden is measured by the degree of relatives' feelings of being disturbed when caring, with items ranging from 1 (not at all) to 4 (very much). Objective and subjective burden are calculated as the average of their respective items. ${ }^{12}$

We used the Statistical Package for the Social Sciences (SPSS) version 21 to perform data analysis. Pearson correlations ( $r$ ) were calculated between FBIS objective or subjective scores and each sociodemographic or clinical variable. For caregiver and patient kinship (parent/nonparent), Pearson point-biserial correlation was assessed $\left(r_{p b}\right)$. We performed linear regression analysis to predict burden (dependent variable), considering all predictors (independent variables) significantly correlated with FBIS subscales. A stepwise procedure was employed to examine the variance accounted for by each independent variable.

\section{Results}

Overall, the majority of the sample of caregivers were female $(74.2 \%)$ and mothers were the most frequent category of caregivers (35.4\%). The mean age of patients was 39.8 (standard deviation [SD] = 13) years and they had a mean of $6.94(S D=3.2$ ) years of formal education. Males accounted for $58.1 \%$ of patients. In addition to being 
clinically stable at assessment time, 29 subjects (93.5\%) had not exhibited a psychotic crisis in the previous 12 months, defined as no hospital admissions during the period. Eighteen patients (58.1\%) were taking typical antipsychotics, 9 (29\%) were taking atypical antipsychotics and the remainder were taking both types, with a mean chlorpromazine equivalent of 352.3 (SD = 181.6) $\mathrm{mg} / \mathrm{d}$; 17 patients $(54.8 \%)$ also had prescriptions for other drugs, including antiparkinsonian agents.

Descriptive data and Pearson coefficients for correlations between family burden, and sociodemographic and clinical measures are detailed in Table 1. Objective and subjective FBIS scores were $1.9(\mathrm{SD}=0.5)$ and 2.4 (SD $=0.6)$ respectively. Thirteen patients' $(41.9 \%)$ caregivers were their parents. The mean age of schizophrenia onset was 24.1 ( $S D=7.4$ ) years, and patients accounted for an average of $20 \%$ of the total family income. FBIS objective score correlated positively and significantly with positive ( $r$ $=0.388, p<0.05)$, negative $(r=0.550, p<0.05)$ and cognitive $(r=0.553, p<0.01)$ symptoms. FBIS subjective score correlated significantly and positively with positive symptoms ( $r=0.401, p<0.05)$, and negatively with age of disease onset $(r=-0.453, p<0.05)$. Although the type of caregiver (parent/non-parent) appeared to only exhibit a tendency to positive correlation with FBIS subjective score $\left(r_{p b}=0.353, p=0.05\right)$, we nevertheless included it in the regression analysis to avoid type 2 errors. Patient/family income ratio did not correlate with FBIS.

Applying a simultaneous entry regression procedure to FBIS objective score, overall results were significant, $F_{(3,27)}$ $=8.18, \mathrm{p}=0.000$, with the three independent variables (positive, negative and cognitive symptoms) accounting for a total of $47.6 \%$ of variance. In the stepwise procedure, negative symptoms accounted for $30.3 \%$ of the variance in FBIS objective score $(p=0.000)$. None of the other variables entered the final equation.

For FBIS subjective score, an overall analysis for age of onset, parents as caregivers and positive symptoms entered simultaneously as independent variables in regression was also significant, $F_{(3,27)}=3.51, p=0.029$, accounting for $a$ total of $28 \%$ of variance. With a stepwise analysis, age of onset contributed for $20.3 \%$ of variance $\left(F_{(1,29)}=7.39\right.$ [p $=$ $0.011]$ ), while the remaining variables did not account for significant additional variance.

\section{Discussion}

This preliminary study was designed to investigate sociodemographic and clinical variables to identify predictors of family burden. Since our sample is relatively small ( $n=31)$, an effort was made to select a small number of representative variables, based on previous data and correlation analysis.

Three clinical variables (negative, positive and cognitive symptoms) significantly correlated with and strongly predicted objective burden. Rabinowitz et al. ${ }^{5}$ found that the coexistence of prominent positive and negative symptoms was associated with increased burden, and Roick et al. ${ }^{6}$ also linked these symptoms, along with sociodemographic aspects, to caregiver burden. However, neither of these studies considered cognitive symptoms or differentiated the objective and subjective aspects of burden. Our results also show that when symptoms were analyzed together in a stepwise regression model, only negative symptoms remained significantly related to the FBIS objective score. This suggests that caregivers may spend more time and energy on compensating patients' motivational issues than on overcoming incompetence or disruptive behavior.

Table 1 - Descriptive data and Pearson coefficients for correlations between family burden and sociodemographic and clinical variables

\begin{tabular}{|c|c|c|c|c|c|c|c|}
\hline \multirow[b]{2}{*}{ Measure } & \multirow[b]{2}{*}{$\begin{array}{c}\text { Descriptive } \\
\text { data }(n=31) \\
\text { Mean (SD) }\end{array}$} & \multicolumn{6}{|c|}{ Pearson correlation (r) } \\
\hline & & $\begin{array}{l}\text { Caregiver } \\
\text { is parent }\end{array}$ & $\begin{array}{c}\text { Disease } \\
\text { onset }\end{array}$ & $\begin{array}{c}\text { Patient/ } \\
\text { family } \\
\text { income }\end{array}$ & $\begin{array}{c}\text { PANSS } \\
\text { positive } \\
\text { total score }\end{array}$ & $\begin{array}{c}\text { PANSS } \\
\text { negative } \\
\text { total score }\end{array}$ & $\begin{array}{c}\text { SCoRS } \\
\text { interviewer } \\
\text { score }\end{array}$ \\
\hline FBIS objective total score & $1.9(0.5)$ & $0.228 *$ & -0.171 & 0.141 & $0.388+$ & $0.550 \neq$ & $0.553 \neq$ \\
\hline FBIS subjective total score & $2.4(0.6)$ & $0.353 *+$ & $-0.451+$ & -0.95 & $0.401+$ & 0.196 & 0.084 \\
\hline Caregiver is parent, $\mathrm{n}(\%)$ & $13(41.9)$ & & $-0.526 * \neq$ & $-0.579 * \neq$ & $0.324 *$ & $0.170 *$ & $-0.140 *$ \\
\hline Disease onset, age & $24.1(7.4)$ & & & $0.450 *$ & -0.349 & -0.120 & 0.041 \\
\hline Patient's/family's income & $0.2(0.3)$ & & & & -0.353 & -.0 .118 & $0.445+$ \\
\hline PANSS positive total score & $9.5(2.9)$ & & & & & $0.391+$ & -0.034 \\
\hline PANSS negative total score & $19.5(7.1)$ & & & & & & $0.544 \neq$ \\
\hline SCoRS interviewer score & $37.5(10.7)$ & & & & & & \\
\hline
\end{tabular}

SD = standard deviation; FBIS = Family Burden Interview Schedule; PANSS = Positive and Negative Syndrome Scale; SCoRS = Schizophrenia Cognition Rating Scale.

* Pearson point-biserial correlation (rpb).

$+\mathrm{p} \leq 0.05$ two tailed.

$\neq p<0.01$ two tailed. 
Grandón et al. ${ }^{13}$ described a different pattern, in which negative symptoms did not contribute to predicting burden, whereas positive symptoms and functional disability were retained in the final regression equation. Similar findings were reported by Ochoa et al. ${ }^{3}$ for objective burden. These differences may be related to the fact that those studies included functioning as a variable. Since it is strongly determined by both cognitive and negative symptoms, ${ }^{14}$ it may overlap and superimpose on its determinants in the regression model, which could also favor positive symptoms. Interestingly, cognitive impairment also moderately and positively correlated with patients' contribution to total family income, which may be explained by greater provision of disability benefits to a more impaired population.

Besides objective burden, positive symptoms also correlated with subjective burden, possibly due to its potential to disrupt daily routines and cause caregivers embarrassment or negative feelings. A relationship between earlier onset of schizophrenia and higher levels of subjective burden among caregivers, especially parents, was also observed. Similar findings were described by Roick et al. ${ }^{6}$ in both Britain and Germany. In a culturally comparable sample of Brazilian patients, Albuquerque et al. ${ }^{15}$ found no difference between groups of family caregivers with regard to burden, but parents reported more time and money spent and more concerns about the future. However, only age of onset survived as an independent predictor of subjective burden. A Spanish study ${ }^{3}$ also found out that, along with age, disability, and negative symptoms, age of disease onset contributed to concerns about patients' futures. In fact, the disruption of caring for patients with such a disabling mental disorder may be well summed up by this variable, since younger individuals are not expected to have finished their studies, initiated a career, or achieved an independent life by the time of disease onset.

This study has some limitations. Our small sample limits generalization of results and was not large enough for inclusion of other patient variables as candidate predictors, such as gender or educational level. As a cross-sectional study, nothing can be stated about causality, particularly because family burden can be either consequence or cause of severity of symptoms. Most of the variance of subjective burden remains unexplained and further analyses are necessary, including more detailed caregiver and environmental characteristics. Notwithstanding, our study included a cognitive measure as a variable, instead of a functional one, which appears to have been the right decision considering objective burden and excluding a possible confounding factor of symptoms. We also believe that this is the first study to have directly investigated the relationship between patients' financial contribution and caregivers' burden. Finally, the use of an instrument that assesses objective and subjective burdens separately appears to be desirable since, as shown, these subdomains may be differently impacted by different determinants and therefore require distinct therapeutic approaches.

\section{References}

1. Van Os J, Kapur S. Schizophrenia. Lancet. 2009;374:635-45.

2. Boye $B$, Bentsen $H$, Notland $T H$, Munkvold OG, Lersbryggen $A B$, Oskarsson $\mathrm{KH}$, et al. What predicts the course of expressed emotion in relatives of patients with schizophrenia or related psychoses? Soc Psychiatry Psychiatr Epidemiol. 1999;34:35-43.

3. Ochoa S, Vilaplana M, Haro JM, Villalta-Gil V, Martinez F, Negredo MC, et al. Do needs, symptoms or disability of outpatients with schizophrenia influence family burden? Soc Psychiatry Psychiatr Epidemiol. 2008;43:612-8.

4. Kate N, Grover S, Kulhara P, Nehra R. Caregiving appraisal in schizophrenia: a study from India. Soc Sci Med. 2013;98:135-40.

5. Rabinowitz J, Berardo CG, Bugarski-Kirola D, Marder S. Association of prominent positive and prominent negative symptoms and functional health, well-being, healthcare-related quality of life and family burden: A CATIE analysis. Schizophr Res. 2013;150:339-42.

6. Roick C, Heider D, Bebbington PE, Angermeyer MC, Azorin JM, Brugha TS, et al. Burden on caregivers of people with schizophrenia: comparison between Germany and Britain. $\mathrm{Br}$ J Psychiatry. 2007;190:333-8.

7. Papastavrou E, Charalambous A, Tsangari H, Karayiannis G. The cost of caring: the relative with schizophrenia. Scand J Caring Sci. 2010;24:817-23.

8. Sheehan DV, Lecrubier $Y$, Sheehan $\mathrm{KH}$, Amorim $\mathrm{P}$, Janavs J, Weiller $\mathrm{E}$, et al. The Mini-International Neuropsychiatric Interview (M.I.N.I.): the development and validation of a structured diagnostic psychiatric interview for DSM-IV and ICD-10. J Clin Psychiatry. 1998;59:22-33.

9. Kay SR, Fiszbein A, Opler LA. The positive and negative syndrome scale (PANSS) for schizophrenia. Schizophr Bull. 1987;13:26176.

10. Keefe RS, Poe M, WalkerTM, Kang JW, Harvey PD. The Schizophrenia Cognition Rating Scale: an interview-based assessment and its relationship to cognition, real-world functioning, and functional capacity. Am J Psychiatry. 2006;163:426-32.

11. Bandeira M, Calzavara MGP, Castro I. Estudo de validade da escala de sobrecarga de familiares cuidadores de pacientes psiquiátricos. J Bras Psiquiatr. 2008;57:98-104.

12. Bandeira M, Calzavara MG, Freitas LC, Barroso SM. Family Burden Interview Scale for relatives of psychiatric patients (FBIS-BR): reliability study of the Brazilian version. Rev Bras Psiquiatr. 2007;29:47-50.

13. Grandón $P$, Jenaro $C$, Lemos S. Primary caregivers of schizophrenia outpatients: burden and predictor variables. Psychiatry Res. 2008; 158:335-43.

14. Bowie $C R$, Reichenberg $A$, Patterson $T L$, Heaton RK, Harvey PD. Determinants of real-world functional performance in schizophrenia subjects: correlations with cognition, functional capacity, and symptoms. Am J Psychiatry. 2006;163:418-25.

15. Albuquerque EPT, Cintra AMO, Bandeira M. Sobrecarga de familiares de pacientes psiquiátricos: comparação entre diferentes tipos de cuidadores. J Bras Psiquiatr. 2010;59:308-16.

\section{Correspondence:}

Lucas M. Mantovani

Av. do Contorno, 3017, Santa Efigênia

30110-080 - Belo Horizonte, MG - Brazil

Tel. : +55 (31) 3239.9900

E-mail: Immantovani@gmail.com 